\title{
A CONSTITUIÇÃo DE ALEGRETE NA HISTÓRIA CONSTITUCIONAL BRASILEIRA: UMA ANÁLISE A PARTIR DA SOCIOLOGIA DAS CONSTITUIÇÕES
}

Bernardo Leandro Carvalho Costa ${ }^{1}$

Resumo: o presente trabalho tem como objetivos contextualizar e analisar, no âmbito da Teoria Constitucional e da Sociologia das Constituições, o surgimento da Constituição Brasileira de 1824 e do projeto de institucionalização da Revolução Farroupilha, a Constituição de Alegrete. Nessa proposta, por meio da metodologia sistêmica e da técnica de pesquisa de documentação indireta, revisando bibliografia nacional e estrangeira, busca-se verificar se o projeto apresentado à assembleia constituinte da República Rio-Grandense representava, em matéria constitucional, os ideais que fundamentaram a eclosão do ato revolucionário em 1835, apresentando uma oposição consistente em relação à estrutura presente na primeira Constituição Brasileira.

Palavras-chave: Constituição de Alegrete; Constituição Brasileira de 1824; Constitucionalismo Social; Revolução Farroupilha; Sociologia das Constituições; Teoria dos Sistemas Sociais;

\section{THE CONSTITUTION OF ALEGRETE IN BRAZILIAN CONSTITUTIONAL HISTORY: AN ANALYSIS THROUGH THE SOCIOLOGY OF CONSTITUTIONS}

\begin{abstract}
The purpose of this work is to contextualize and analyze, within the framework of Constitutional Theory and Sociology of Constitutions, the emergence of the Brazilian Constitution of 1824 and the institutionalization project of the Farroupilha Revolution, the

1 Doutorando em Direito Público pelo Programa de Pós-Graduação em Direito da Unisinos. Bolsista Capes/PROEX. Membro de grupo de pesquisa Teoria do Direito (CNPq). Possui experiência nas áreas de Teoria Constitucional e Sociologia Jurídica, atuando principalmente nos seguintes temas: Constitucionalismo Social, Sociologia das Constituições e Teoria dos Sistemas Sociais. bernardoleandro@me.com.
\end{abstract}


Constitution of Alegrete. In this proposal, it uses the sociological systemic theory to verify if the project of Constitution of Alegrete, in constitutional matters, has the ideals that boosted the Farroupilha Revolution in opposite of the first Brazilian Constitution.

Constitution of Alegrete; Brazilian Constitution of 1824; Social Constitutionalism; Farroupilha Revolution; Sociology of Constitutions; Social Systems Theory;

\section{INTRODUÇÃO}

Em resposta ao contexto das revoluções liberais do século XVIII, o início do constitucionalismo, em perspectiva de Constituições escritas, ocorreu no Brasil do século XIX, quando o país recebeu o seu primeiro projeto de Constituição. Como produto dessa proposta, a carta outorgada de 1824, no ambiente de uma assembleia constituinte dissolvida pela força militar do imperador D. Pedro I, foi alvo de severas críticas à época, que impulsionaram uma série de movimentos de resistência em diversas províncias.

Como oposição ao modelo centralizador da Constituição de 1824, no ano de 1835 , eclodiu a Revolução Farroupilha no Sul do país. Entre os fundamentos teóricos elencados como propulsores da Revolução estavam o federalismo e o liberalismo. Ademais, forte oposição ao modelo do Poder Moderador, instituído pela Constituição Brasileira de 1824, era um argumento levantado pelo movimento revolucionário.

$\mathrm{O}$ problema colocado no presente trabalho refere-se à dificuldade, por um lado, de saber se de fato esses princípios que fundamentavam a oposição ao modelo estatal centralizador do poder estabelecido pela Constituição de 1824 nortearam as tentativas de institucionalização das revoltas em relação à Constituição do Império, enfatizando, neste caso, a Revolução Farroupilha. A busca por esta resposta terá como objeto a Constituição de Alegrete, projeto de Constituição que foi apresentado como tentativa de estabelecimento formal da República Rio-Grandense no ano de 1843, ao longo da Revolução Farroupilha.

Tendo como temas centrais os traços do constitucionalismo presentes nas Constituição Brasileira de 1824 e a Constituição de Alegrete, portanto, o presente trabalho tem como objetivos contextualizar o surgimento desses documentos constitucionais, um em suposta 
oposição ao outro, verificando os elementos teóricos que os impulsionaram, bem como enquadrá-los no contexto de análise da Sociologia das Constituições.

Para tal, far-se-á, inicialmente, uma descrição do surgimento do constitucionalismo caracterizado pela presença de Constituições escritas, embalado pelo movimento revolucionário francês do século XVIII, destacando suas evoluções no contexto teórico do final do século XX, até o surgimento dos estudos em Sociologia das Constituições.

Em momento posterior, será evidenciado o ambiente conturbado de elaboração e outorga da Constituição Brasileira de 1824, como resposta aos impulsos constitucionais do século XVIII.

Na sequência, na onda da série de revoltas ao poder centralizador estabelecido na Constituição de 1824, será demonstrado o contexto de eclosão da Revolução Farroupilha no Rio Grande do Sul em 1835. Como cerne do movimento para análise, far-se-ão considerações sobre a Constituição de Alegrete, documento que buscou estabelecer a independência da República Rio-Grandense. Neste ponto de análise, o objetivo específico será verificar se as tendências presentes no referido documento constitucional correspondem aos princípios norteadores da Revolução Farroupilha.

A presente pesquisa justifica-se no intuito de resgatar o contexto de surgimento das Constituições no Brasil, com destaque para o ambiente que ocasionou a Constituição Brasileira de 1824. Nessa linha, relevante demonstrar como diversos movimentos de oposição eclodiram no território brasileiro na época, com base em aportes filosóficos do próprio constitucionalismo. Nessas propostas, sabe-se que princípios do liberalismo e do federalismo, entre outros, justificavam as oposições ao poder central. Todavia, é escasso o material de análise sobre as tentativas de institucionalização das investidas revolucionárias, principalmente para saber se condiziam com a fundamentação teórica dos movimentos, a exemplo da Constituição de Alegrete, que é um dos objetos do presente trabalho.

Como método de pesquisa, será utilizada a Teoria dos Sistemas Sociais (LUHMANN, 2016), considerando a Constituição como um acoplamento estrutural entre os sistemas do Direito e da Política (COSTA; ROCHA, 2018). Nessa proposta, buscar-se-á enquadrar as Constituições analisadas no âmbito histórico da Sociologia do Constitucionalismo 
(THORNHILL, 2011), observando as tentativas de vinculação das decisões estatais com o fenômeno jurídico à época.

\section{O CONSTITUCIONALISMO E SUAS VARIAÇÕES}

O esboço teórico do constitucionalismo como técnica jurídica de limitação do poder político (BOBBIO, 1987) têm suas origens na França. Carré de Malberg (1948, p. 21), considerando o contexto revolucionário francês de surgimento do fenômeno, descreve a origem do Direito Constitucional a partir do que concebe por Direito Público, aplicável às relações humanas ou sociais que tenha o Estado como parte. As regras que tratam esses casos formam a Constituição do Estado.

Para a Constituição do Estado, há elementos imprescindíveis, como povo e soberania e território. Nas relações de poder exercidas pelo Estado, há um esboço de limitação do poder a partir desses elementos. O Direito Constitucional surge como um ramo do Direito Público (Direito do Estado), considerado: “[...] o direito aplicável a todas as relações humanas ou sociais nas quais o Estado esteja em jogo.” (MALBERG, 1948, p. 21) (tradução nossa). No âmbito interno do Direito Público há uma “[...] a parte do direito público que trata das regras ou instituições cujo conjunto forma em cada meio estatal a Constituição do Estado [...]” (MALBERG, 1948, p. 21) (tradução nossa).

Na Alemanha, Jellinek (2000, p.274) destaca a origem francesa do constitucionalismo, que depois chegará ao território alemão sob forte influência das invasões napoleônicas, enfatizando que a síntese dos elementos caracterizadores do Estado representam a aplicação, por este, do imperium estatal sobre os súditos que estão conectados a determinado espaço territorial, com suas permissões e proibições, típicas do Direito Público.

Como se vê, a origem do constitucionalismo conecta o Direito Constitucional ao Direito Público e à Teoria do Estado, a partir de seus elementos constitutivos. A maior vinculação do constitucionalismo nesse momento histórico refere-se à necessidade de um documento constitucional escrito, elaborado por uma assembleia constituinte, nas bases teóricas da proposta de Siéyés (1986). 
Traço forte de referida influência é o próprio texto da Declaração dos Direitos do Homem e do Cidadão (DECLARAÇÃO, 2018). O artigo 16 explicitamente menciona que "Qualquer sociedade em que não esteja assegurada a garantia dos direitos, nem estabelecida a separação dos poderes não tem Constituição (artigo 16)."

Portanto, as análises constitucionais, na origem do fenômeno, já destacavam a necessidade de observar os textos escritos para verificar o padrão de constitucionalidade. Em síntese, para saber se havia Constituição, bastava uma análise do documento constitucional. Se estivesse lá estabelecidas a separação dos poderes e a garantia dos direitos, se estava falando de uma Constituição.

As constituições elaboradas pelos diversos países ao longo do tempo podem ser classificadas como presentes em diferentes etapas constitucionais. Em termos de Direito Comparado, Di Ruffia (1998, p. 93) afirma que as Constituições a serem analisadas no presente trabalho enquadram-se na etapa do constitucionalismo clássico:

Em consequência, pode-se demonstrar que a etapa do "constitucionalismo clássico" se desenvolveu no mundo moderno entre 1787 e o fim da primeira Guerra Mundial de acordo com cinco "ciclos sucessivos", por meio de uma série de conceitos e realizações que se percebem facilmente em sua progressividade linear, incluindo as seguintes Constituições: revoluções do século XVIII (1789-1799), napoleônicas (1799-1815), da Restauração (1815-1830), liberais (1830-1848) e democráticas (1848-1918), entre elas várias de caráter federal (1848-1874); porém a partir de então as Constituições tem se orientado em direções diversas e contrastantes. (tradução nossa).

As construções constitucionais do século XX não destoam desse padrão. Apesar das relevantes discussões entre Kelsen (2003) e Schmitt (1983) acerca de quem deve exercer a guarda da Constituição, a referência a um documento único que delimita o exercício do poder pelo Estado dentro de seu território é constante. Para Kelsen (2003, p. 131), a Constituição “[...] é a norma que rege e elabora as leis, das normas gerais para cuja execução se exerce a atividade dos organismos estatais, dos tribunais e das autoridades administrativas." Não há, portanto, uma distinção entre Constituições formais e materiais, classificação posteriormente 
analisada por importantes autores da Sociologia do Constitucionalismo, a exemplo de Febbrajo (2016).

No tocante a esse ponto, não há grandes divergências na obra de Schmitt (2007), fortemente vinculada ao contexto de Constituições escritas. A divergência presente no debate refere-se ao controle constitucional das leis. Para o autor:

Conforme o direito positivo da Constituição de Weimar, a posição do presidente do Reich, eleito pela totalidade do povo, só pode ser construída com a ajuda de uma teoria mais desenvolvida de um poder neutro intermediário, regulador e preservador. O presidente do Reich está munido de poderes que o tornam independentes dos órgãos legislativos, embora esteja vinculado, simultaneamente, à referenda dos ministros independentes da confiança do parlamento. (SCHMITT, 2007, p. 201).

Por outro lado, para Kelsen (2003, p. 150):

Portanto não é com o próprio Parlamento que podemos contar para efetuar sua subordinação à Constituição. É um órgão diferente dele, independente dele e, por conseguinte, também de qualquer outra autoridade estatal, que deve ser encarregado da anulação de seus atos inconstitucionais- isto é, uma jurisdição ou um tribunal constitucional.

Resumindo, o grande debate constitucional do século XX é elaborado a partir da distinção acerca de quem deve ser o guardião da Constituição, como demonstrado acima na divergência entre Kelsen (2003) e Schmitt (2007), análises apegadas ao contexto de Constituições escritas nos Estados nacionais.

Em um tipo diferente de observação, impulsionado pelo avanço do fenômeno da globalização ocorrido no final do século XX, os recentes estudos em Sociologia do Constitucionalismo concebem a Constituição como o vínculo de interconexão das decisões políticas do Estado (Sistema da Política) com a necessária fundamentação jurídica de referidas decisões (Sistema do Direito). Tal proposta parte do referencial teórico da Teoria dos Sistemas Sociais de Luhmann (2016).

A primeira distinção importante dessa proposta é elucidada por Febbrajo (2016), ao diferenciar o âmbito das Constituições formais, no qual se inserem as análises constitucionais das origens até o final do século XX, como Kelsen (2003) e Schmitt (2007), e o das 
Constituições materiais, cuja análise passou a ser imprescindível a partir da expansão do fenômeno da globalização.

Para Febbrajo (2016, p. 58):

[...] a distinção entre a Constituição formal e a material é estritamente ligada à distinção entre a Constituição como é declarada e como ela é socialmente implementada; que uma abordagem sociojurídica tem de definir, de um lado, as diferenças estruturais e, por outo, as possíveis complementariedades funcionais entre a ordem normativa estatal e as muitas ordens normativas coexistindo em uma dada sociedade.

Envolvido em elementos da teoria sociológica do Constitucionalismo Social (SCIULLI, 1988), atualmente revisitados por Teubner (2016), Febbrajo (2016) destaca essa diferença entre a existência de textos constitucionais (Constituições formais) e de estruturas que exercem relações de poder na sociedade, caracterizando as Constituições materiais. Sendo assim:

A Constituição material é concebida em sentido amplo e em sentido estrito. No primeiro, identifica-se com a organização total do Estado, com regime político. No segundo, designa as normas constitucionais escritas ou costumeiras, inseridas ou não num documento escrito, que regulam a estrutura do Estado a organização de seus órgãos e os direitos fundamentais. (FEBBRAJO, 2016, p. 71).

Nesse âmbito de estudos em Sociologia das Constituições, Thornhill (2011) afirma que, a partir de determinado ponto da história, o que Luhmann (2016) concebe como sociedade moderna, é possível observar que as decisões do Sistema da Política estão estritamente vinculadas a comunicações do Sistema do Direito. Nesse contexto é possível falar de Constituição, mesmo antes dos tradicionais documentos escritos constitucionais que surgiram ao longo do século XVIII, com destaque para os Estados Unidos e a França.

Quando a organização do Sistema da Política (Estado) atua conforme as disposições presentes no Sistema do Direito, guiado pelas disposições constitucionais, portanto, pode-se dizer que há um acoplamento estrutural estre os sistemas do Direito e da Política, representado pela Constituição, que realiza uma ponte sistêmica em relação a esses âmbitos. (ROCHA; COSTA, 2018).

Nessa perspectiva, fala-se em dois diferentes sistemas da sociedade mundial que se reproduzem de maneira autônoma (autopoiese). Nesse sentido, o Sistema da Política, toma decisões coletivamente vinculantes por meio de mandatários legitimados para isso 
(democracia), ao passo que o Sistema do Direito seleciona e estrutura expectativas presentes no seu entorno, traduzidas em direitos no interior do Sistema.

Autopoiese e acoplamento estrutural, portanto, são elementos que caracterizam a concepção sistêmica de constitucionalismo, na medida em que representam, ao mesmo tempo, autorreferência e dependência no atuar dos sistemas da Política e do Direito. Cada decisão do Estado enquanto organização do Sistema da Política será legítima/ constitucional, na medida em que estiver baseada em um pressuposto jurídico, conectada ao código do Sistema do Direito. Esse ato não deixa de ser uma decisão autônoma do Sistema da Política, mas também está conectada (acoplada estruturalmente) ao Sistema do Direito.

As análises desse âmbito constitucional de decisões políticas é o objeto da Sociologia do Constitucionalismo. Mesmo assim, não necessitando de um documento escrito para se considerar a existência de uma Constituição, a positivação de direitos em documentos constitucionais é de extrema importância para os estudos sobre o tema, não havendo uma necessária exclusão entre as perspectivas de análise normativas e sociológicas (THORNHILL, 2016).

Nesse sentido, como destacam Rocha e Costa (2018, p.45):

A Constituição, portanto, medeia as relações entre os sistemas sociais da Política e do Direito, possibilitando uma observação sistêmica do Direito Constitucional. Essa interpenetração entre os sistemas (acoplamento estrutural)- como já destacado acima- é feita pela Constituição e pode ser observada a partir de um contexto histórico, com o próprio surgimento do Estado, portador desse acoplamento estrutural entre os sistemas da Política e do Direito, cuja condição para tal é a existência de uma Constituição capaz de permitir que o direito positivo se converta em um meio de conformação política, bem como que o Direito Constitucional possa, nesses termos, se tornar instrumento jurídico para a implantação de uma disciplinarização política.

Há casos, todavia, em que o texto constitucional funciona apenas como instrumento simbólico para os mandatários do poder. Na sociedade, ao contrato do que está positivado, os Sistemas Sociais envolvidos na necessária relação sistêmica, a exemplo da Política e do Direito, não funcionam de maneira autônoma, muitas vezes um determinando o modo de atuar do outro. Ao contrário da autopoiese, trata-se de um movimento de alopoiese (ausência de 
autonomia). Nesse cenário, Marcelo Neves (1994) diz que há um processo de constitucionalização simbólica.

Nesse contexto é que se enquadra a análise proposta no presente trabalho, evidenciando o quadro de surgimento da primeira Constituição Brasileira, com ênfase para as propostas efetivamente colocadas no texto constitucional e a caracterização dos desdobramentos fáticos ao longo do processo constituinte, em um balanço ao mesmo tempo normativo e sociológico do episódio.

Em termos semelhantes, após observações sobre os desdobramentos e frustrações oriundos do primeiro processo constituinte brasileiro, evidencia uma das tentativas de resistência à malfadada Constituição outorgada de 1824. Nessa perspectiva, contextualiza o surgimento da Revolução Farroupilha no Rio Grande do Sul em 1835, destacando, nesse movimento, o projeto de Constituição, conhecido como "Constituição de Alegrete" que institucionalizaria o processo de independência tentado com o fato, apontando, nessa análise normativa e sociológica, as curiosidades e contradições do Processo.

\section{A CONSTITUINTE DO IMPÉRIO: INFLUÊNCIAS E REPERCUSSÃO DA PRIMEIRA CONSTITUIÇÃO DO BRASIL}

Como visto acima, essa tradição iniciada na França espalhou-se rapidamente pela Europa impulsionada pelas invasões de Napoleão, como destaca Jellinek (1948). E o Brasil? Qual foi a primeira aproximação em relação ao fenômeno constitucional que rapidamente tomava conta do continente europeu?

Com forte influência da Revolução Francesa (1789), ideais libertadores e contra o absolutismo espalharam-se pelo Brasil no início do século XIX, com destaque para as diversas iniciativas revolucionárias no território brasileiro, entre as quais estavam a Inconfidência Mineira e a Revolução Pernambucana de 1817, com forte inspiração nos ideais da França na época. (BONAVIDES, 1991, p. 31).

Como resposta a esse contexto de insurgência, antes mesmo do movimento de independência do Brasil, sob a regência de D. Pedro I, o decreto de 03 de junho de 1822 propôs a criação de uma Assembleia Luso-Brasiliense, que concentraria as atividades 
constitucionais e legislativas (criação da Constituição e de leis ordinárias) nas mãos de deputados das províncias brasileiras. Era o esboço da primeira Constituição brasileira.

Ao mesmo passo que se tentava dar uma resposta aos movimentos revolucionários com inspiração nos ideais de liberdade, a Constituinte proposta contradizia a ideia de poder constituinte elaborada por Siéyés (1986) na França, uma vez que as atividades constituintes não foram atribuídas a uma assembleia exclusiva. Ademais, ainda que espelhada nos textos constitucionais do período revolucionário francês (de 1791, 1793 e 1799) e na Constituição Espanhola de 1812, a proposta brasileira sofreu influências ainda mais fortes da Constituição francesa da Restauração (1814), que em muitos aspectos se opôs aos ideais da Revolução Francesa (NEVES, 2018, p.173).

O movimento de independência, em 07 de setembro de 1822, sucedeu a proposta constituinte, mas ocorreu sem a costumeira ruptura revolucionária, ocorrida em outros países da América. D. Pedro I, o príncipe regente, foi a figura encarregada de conduzir o processo de elaboração da primeira Constituição após a independência, motivo pelo qual sua atuação é fundamental para compreender o contexto da Constituinte.

D. Pedro I sucedeu a D. João VI, cujas ideias trazidas com a fixação da Corte Portuguesa em no Brasil em 1808 representavam os ideais de um Estado fortemente centralizado. Nessa proposta, D. Pedro I foi encarregado de defender os interesses portugueses em terras brasileiras, sem que o movimento de independência atrapalhasse esse processo.

A partir da figura histórica de D. Pedro I, é possível destacar dois momentos destoantes de sua atuação nas atividades da regência ao longo do processo constituinte que culminaria na Constituição de 1824. Inicialmente, influenciado por José Bonifácio de Andrada e Silva, o Patriarca da Independência, personalidade fundamental nesse período (BARRETO, 1977) e demais representantes da família dos Andradas, observa-se, em sua atuação, uma inclinação aos ideais de um liberalismo monárquico e moderado, voltado para a independência do Brasil, inspirado em Montesquieu, Burke e Constant, representando ideias que circulavam na Europa. Posteriormente, após a ruptura com os Andradas, observa-se uma inclinação para os ideais traçados pelo "Partido Português", representado por atores lusos no Brasil, com simpatia a ideais absolutistas e autoritários. (BONAVIDES, 1991, p. 47). 
A ruptura de D. Pedro I com os Andradas, marcada por uma série de acusações do príncipe regente dirigidas ao patriarca da independência culminaram em uma série de discussões no interior da Assembleia Constituinte, com respostas às críticas feitas pelo imperador.

Nesse cenário de acirradas discussões, um assunto de grande repercussão deu-se no tocante ao juramento prévio da Constituição. A Assembleia Constituinte em comento representava a iniciativa de consolidar e institucionalizar o processo de independência do Brasil. Todavia, antes mesmo da existência de uma Constituição, já havia um imperador, cuja autoridade preexistia ao próprio texto constitucional. A discussão sobre este aspecto também representou uma ameaça a D. Pedro, que não admitiu que seu poder fosse retirado- ou sequer limitado- pela Assembleia Constituinte. (PICCOLO, 1985, p. 36)

O impulso militar e autoritário de D. Pedro I, reforçando os ideais do "Partido Português" dissolveu a assembleia constituinte, cujos membros só pararam as críticas ao imperador pela "força das baionetas" (BONAVIDES, 1991, p. 740).

Nesse contexto, surgiu a primeira Constituição do Brasil, a carta outorgada do império de 1824, cuja característica mais marcante foi a presença de um Poder Moderador, personificado na figura do Imperador como mediador das relações entre os poderes, inspirado na doutrina constitucional de Benjamin Constant, além de manter os traços de um Estado centralizado, com pouca autonomia às províncias.

Em relação ao Poder Moderador, Marcelo Neves (2018, p. 172) faz uma síntese de suas atribuições na Constituição de 1824:

O Poder Moderador era superior aos três poderes clássicos. Em seu exercício, o rei podia, simultaneamente, dissolver a Câmara dos Deputados e suspender ou adiar a Assembleia Geral (Senado + Câmara dos Deputados) (art. 101, V), nomear e demitir livremente os ministros (art.101, VI) e suspender os juízes (art. 101, VII).

Em termos de Sociologia das Constituições (THORNHILL, 2011), pode-se afirmar que a Constituição de 1824, em relação à ausência de independência sistêmica (diferenciação funcional) que caracterizava a sociedade da época, é dotada de forte caráter simbólico. Nesse sentido, ainda que o Projeto de Constituição possuísse traços oriundos do liberalismo, de fato, 
ainda que promulgada fosse a Constituição, não conseguiria ameaçar a estrutura oligárquica do Brasil. (NEVES, 2018, p. 171).

Nesse sentido, afirma Marcelo Neves (2018, p. 177) que:

Do ponto de vista sistêmico-teórico, trata-se da subordinação do direito ao código do poder mediante o uso "simbólico-legitimador" do texto constitucional por parte do sistema político, tudo isso por falta dos pressupostos sociais para a positivação do direito. Isso não implica, de modo nenhum, a insignificância da Carta Constitucional como um 'um painel decorativo' $[\ldots]$

Fato é que, apesar de seu caráter simbólico, diversas características presentes no referido documento constitucional serviram de fundamento para diversas revoltas no momento posterior à outorga da Constituição, destacando-se, nesses elementos, o modo de designação dos presidentes das províncias, diretamente pelo poder central, não mais pelas assembleias provinciais, e autonomia para a criação de impostos sem consulta prévia às províncias (FREITAS, 1985, p. 130).

No tocante aos referidos elementos, em confronto com as características da sociedade na época, podem ser apontadas diversos elementos de contradição entre o que foi positivado e o que estava presente no contexto social. Nesse confronto, a oposição entre liberalismo, como ideal propulsor do período, e a escravidão existente no Brasil naquele período, talvez seja o elemento mais característico da constitucionalização simbólica:

Em contradição com essa novidade na "divisão de poderes", o texto constitucional de 1824 caracterizava-se pelo liberalismo das garantias dos direitos fundamentais civis e políticos (art. 179). Mas a escravidão encontrava apoio na Carta mediante a distinção entre cidadãos ingênuos (nascidos livres) e libertos nos termos do art. 6, I. Por outro lado, o direito de voto muito limitado por critérios econômicos (arts. 92-95) e a inexistência de garantia do voto secreto transformavam o sistema em privilégio das oligarquias. (NEVES, 2018, p. 173).

A conjuntura marcada pela dissolução da primeira tentativa de assembleia constituinte no Brasil acirrou-se cada vez mais, arrastando D. Pedro I a níveis extremos de impopularidade que culminaram com a abdicação em 07 de abril de 1831. Nessa perspectiva de resistência ao que acontecia eclodiram diversas revoltas no território brasileiro, destacando-se um forte foco do liberalismo em Pernambuco, liderado por Frei Caneca, um frade Carmelita, na época o maior constitucionalista do país. (BONAVIDES, 1985, p. 79). 


\section{A CONSTITUIÇÃO DE ALEGRETE NA HISTÓRIA CONSTITUCIONAL BRASILEIRA: UMA ANÁLISE A PARTIR DA SOCIOLOGIA DAS CONSTITUIÇÕES}

No âmbito das diversas revoltas que ocorriam no Brasil está a Revolução Farroupilha, impulsionada por fatores políticos e culturais no Estado do Rio Grande do Sul. Com início em 20 de setembro de 1835, com a proclamação da República Rio-Grandense, destaca-se, nesse processo histórico, a elaboração de uma carta constitucional, a Constituição de Alegrete, cujo contexto e as características serão demonstrados a seguir.

\section{A REVOLUÇÃO FARROUPILHA E A CONSTITUIÇÃO DE ALEGRETE}

O decênio iniciado no ano de 1831 com a abdicação de D. Pedro I é marcado por uma série de revoltas no território brasileiro. Tendo como principal elemento a característica centralizadora do Estado brasileiro na época, a Revolução Farroupilha, iniciada em 1835, foi um dos maiores conflitos enfrentados pelo império brasileiro no século XIX.

Nessa época, o atual Estado do Rio Grande do Sul era caracterizado pela força quase que absoluta da pecuária em seu desenvolvimento econômico, com destaque para as produções das charqueadas escravistas, fornecedores da carne de charque para o mercado interno brasileiro. Por outro lado, a nível nacional, o setor cafeicultor desenvolvido no centro do país, produzia para o mercado internacional. Nessa inversão, o avanço das atividades desenvolvidas pelo Rio Grande do Sul, basicamente a pecuária, era dependente de alterações de preços realizadas nos mercados de Rio de Janeiro e Santos, que centralizavam as decisões sobre esse tema.

Sem qualquer gerência sobre o tema, cujas decisões políticas cabiam às elites locais do centro do país, em estrita conexão com o poder central, os produtores locais observavam atos de injusta tributação sobre o charque nacional, ao passo que a entrada desse produto oriundo do exterior era facilitada. Essa divergência de interesses na política econômica em relação ao poder central, com total subordinação do Estado do Rio Grande do Sul é o principal fator que desemboca na Revolução Farroupilha. Nesse sentido: "Os produtores sulinos, por seu lado, defendiam também uma política discriminada de impostos, mas às inversas: protecionismo para os artigos locais, impedindo a entrada dos concorrentes estrangeiros e barateando o acesso do sal no mercado interno brasileiro.” (PESAVENTO, 1985, p. 13)

Rev. Brasileira de História do Direito | e-ISSN: 2526-009X| Goiânia| v. 5 | n. 1 | p. 21-42 | Jan/Jun. 2019 
Baseada nos atributos de autonomia tributária estabelecidos na Constituição de 1824, já em fase de resistência ao texto por várias províncias, o poder central toma derradeiras medidas que atingem diretamente o Estado do Rio Grande do Sul na época. Como afirma Décio Freitas (1985, p.116):

Em 1985, o governo central tomou duas medidas consideradas intoleráveis pelos estancieiros gaúchos: criou um imposto territorial rural e destituiu subitamente os dois comandantes da fronteira. Afora, os estancieiros teriam de pagar mais impostos e ficavam ao mesmo tempo impossibilitados de continuar o contrabando de gado. A resposta foi a rebelião.

Caracterizada como uma rebelião de senhores de terra e gado do Rio Grande do Sul em oposição à dominação oligárquica do centro do país, impulsionadas pelos fatores acima expostos, a Revolução Farroupilha iniciou em 20 de setembro de 1835, a partir da deposição do então Presidente da Província, Antônio Rodrigues Fernandes Braga (BONAVIDES, 1991, p. 177).

Desde o início da história do império brasileiro, caracterizou-se uma divisão entre liberais e conservadores com tendências absolutistas. No Rio Grande do Sul, estruturava-se uma separação entre os defensores do império brasileiro, representados pelo Marquês de Barbacena, e uma oposição a esse grupo, liderada por Bento Gonçalves, principal figura da Revolução Farroupilha. Essa separação deu origem a duas correntes: os legalistas ou caramurus, a favor do império brasileiro, e os farroupilhas, defendendo os interesses do Rio Grande do Sul. (BONAVIDES, 1991, p. 176). Até o final da Revolução Farroupilha, em 1845, uma série de eventos pode ser destacada. Ao presente estudo interessa o processo de formação e institucionalização da Constituição de Alegrete, documento constitucional que regeria a República Rio-Grandense.

Uma vez iniciada a Revolução Farroupilha, a institucionalização do ato de independência em relação ao Brasil ocorreu no aniversário de um ano da Revolução, em 29 de setembro de 1836, em sessão extraordinária na Câmara Municipal de Jaguarão, que declarou a Província "desligada da família brasileira", instituindo um "governo republicano" no território gaúcho. Referido ato foi seguido por outro, oriundo da Câmara de Piratini, em termos semelhantes, no dia 05 de novembro de 1836. (BONAVIDES, 1991, p. 181). 


\section{A CONSTITUIÇÃO DE ALEGRETE NA HISTÓRIA CONSTITUCIONAL BRASILEIRA: UMA ANÁLISE A PARTIR DA SOCIOLOGIA DAS CONSTITUIÇÕES}

Em 06 de novembro de 1836, avançando na questão, a Câmara Municipal de Piratini, após a proclamação de independência novamente, elegeu Bento Gonçalves como presidente da República Rio-Grandense. Tal ato, todavia, foi frustrado pela Batalha da Ilha do Fanfa, ocorrido entre as reuniões das duas câmaras acima citadas, um desastre que resultou com a captura do líder farroupilha pelos legalistas.

Nesse contexto conturbado, de atos de independência e tentativas de formalização da Revolução, com a captura do principal líder no cerne dos acontecimentos, a proposta de elaboração de uma Constituição surgiu apenas sete anos após o início dos fatos- com considerável atraso.

Formada no Município de Alegrete e, por isso "Constituição de Alegrete", a Assembleia Constituinte recebeu o projeto de Constituição da República Rio-Grandense em 08 de fevereiro de 1843. Em termos de formação, convivia com um erro de origem relevante. A exemplo da Constituinte dissolvida por D. Pedro I em 1923, os trabalhos eram realizados por uma Casa que acumulava as atividades constituintes e legislativas, também encarregada de elaborar leis ordinárias. (BONAVIDES, 1991, p. 188).

Em 10 de fevereiro, dois dias após a apresentação do Projeto, a Assembleia Constituinte se dissolveu por iniciativa própria, sem ao menos propor discussões sobre a proposta de Constituição Rio-Grandense. O conteúdo do texto apresentado trazia a transposição de ideias e princípios liberais de Locke, a aplicação da separação de poderes e uma tentativa de compatibilização com o federalismo proposto na instauração da Revolução Farroupilha (BONAVIDES, 1991, p. 188).

Apesar de dissolvida a Assembleia Constituinte antes mesmo da análise da proposta, o projeto apresentado evidenciou a distância entre os ideais proclamados na Revolução e a tentativa de institucionalização da independência. Destoando dos princípios vinculados ao federalismo esboçados pela Revolução Farroupilha, a pretensa Constituição Rio-Grandense propunha a criação de uma república unitária e não federativa.

Em relação aos ideais do liberalismo, cabe destacar a convivência com o contexto de forte escravidão no sul do país. Nesse sentido, a Constituição de Alegrete conferia status de cidadão apenas aos homens livres, sem sequer mencionar escravos ou libertos:

A análise do projeto da Constituição da República dos farroupilhas constituise em outra importante fonte para a pesquisa da atitude dos revolucionários

Rev. Brasileira de História do Direito | e-ISSN: 2526-009X| Goiânia| v. 5 | n. 1 | p. 21-42 | Jan/Jun. 2019 
frente à questão servil. Considera-se cidadão, no projeto, apenas os homens livres, não sendo sequer mencionados os libertos e escravos. Pode-se inferir apenas a inclusão dos libertos na condição de cidadão através do parágrafo $3^{\circ}$ do art. 6, que diz serem cidadãos rio-grandenses todos os brasileiros residentes no território da República na época em que se proclamou a Independência, que aderiram a esta expressa ou tacitamente pela continuação de sua residência bem como todos os outros brasileiros, que atualmente estão empregados no serviço civil e militar da República. (BAKOS, 1885, p. 84)

Nesse cenário, nem sequer a autonomia municipal aparecia. As Câmaras Municipais eram mencionadas como corporações meramente administrativas, evidenciando os efeitos de uma concentração de poder político dentro do território do Rio Grande do Sul, repetindo diversas características centralizadoras do império brasileiro, cujas críticas deram origem à Revolução Farroupilha. (BONAVIDES, 1991, p. 191).

\section{CONSIDERAÇÕES FINAIS}

Tendo como temas centrais os traços do constitucionalismo presentes na Constituição Brasileira do Império de 1824, contraposta por diversos movimentos de revolta no Brasil do século XIX, bem como o surgimento histórico dessa técnica de limitação do poder por meio de um documento único, além das diferentes ramificações de estudos oriundos do Direito Constitucional, o presente trabalho destacou três momentos diversos de análises que possibilitaram chegar às considerações finais a seguir expostas.

Em um primeiro momento, observou-se o momento histórico de disseminação do constitucionalismo enquanto técnica presente em Constituições escritas impulsionado na França no final do século XVIII. Com apego forte à presença de presença de determinados elementos nos documentos constitucionais, a exemplo da garantia da separação de poderes, a própria Declaração dos Direitos do Homem e do Cidadão ilustra essa etapa.

$\mathrm{Na}$ sequência, demonstrou-se como os debates constitucionais do século $\mathrm{XX}$, com destaque para Kelsen (2003) e Schmitt (1983), não se desvincularam desses pressupostos, permanecendo ainda conectados aos elementos da Teoria do Estado bem representados pelo trabalho de Jellinek (2000) na Alemanha. 


\section{A CONSTITUIÇÃO DE ALEGRETE NA HISTÓRIA CONSTITUCIONAL BRASILEIRA: UMA ANÁLISE A PARTIR DA SOCIOLOGIA DAS CONSTITUIÇÕES}

Ao final do século XX, todavia, impulsionado pelo fenômeno da globalização, com a consequente disseminação do constitucionalismo para além das fronteiras do Estado nacional (ACKERMANN, 2007), surgem os estudos acerca da Sociologia das Constituições, destacando-se o recente trabalho de Chris Thornhill.

Por meio desse arcabouço teórico de matriz sociológico-sistêmica, é possível observar o fenômeno constitucional para além das Constituições escritas, evidenciando-o a partir das relações entre os sistemas do Direito e da Política. Nesse âmbito é possível concluir, inclusive, que determinados documentos constitucionais existem apenas no papel, representando um simbolismo constitucional à disposição de quem exerce o poder, perspectiva destacada por Marcelo Neves (2018).

$\mathrm{O}$ intuito de referida parte do trabalho foi contextualizar o surgimento do constitucionalismo no Brasil, bem como verificar o momento posterior de sua evolução, com vistas a caracterizar o ambiente de surgimento da Constituição de Alegrete.

Nessa construção teórica, o segundo item do presente trabalho evidenciou o primeiro impulso do constitucionalismo, em vias de Constituição escrita, que ocorreu no Brasil no início do século XIX. Assim, por meio de um decreto datado de 03 de junho de 1822, antes mesmo da Independência, foi proposta a criação de uma Assembleia Luso-Brasiliense.

Como demonstrado, a tentativa surgiu em um contexto conturbado de personificação dos poderes do imperador. A consequência foi a dissolução, por D. Pedro I, da primeira assembleia constituinte brasileira. O resultado possível desse processo foi a Constituição outorgada de 1824.

Buscando aspectos históricos do constitucionalismo, em termos de Direito Comparado, viu-se que referida Constituição enquadra-se no período clássico de formação das constituições (DI RUFFIA, 1998), guardando influências do período revolucionário francês, mas também da época da subsequente Restauração na Europa.

Em âmbito sistêmico de análise da Sociologia das Constituições (THORNHILL, 2011) todavia, há de se concluir que não possuía capacidade para vincular juridicamente as decisões do Sistema da Política (COSTA; ROCHA), não passando de uma Constituição meramente simbólica.

Rev. Brasileira de História do Direito | e-ISSN: 2526-009X| Goiânia| v. 5 | n. 1 | p. 21-42 | Jan/Jun. 2019 
No mesmo item demonstrou-se o forte movimento de resistência ao poder centralizador insculpido na referida carta constitucional. Entre as principais críticas, destacouse a repulsa à figura do Poder Moderador, um quarto poder a cargo do imperador, que desequilibrava as relações políticas no quando estatal. Como consequência, viu-se que surgiu uma série de movimentos espalhados pelo Brasil. Nesse cenário enquadrou-se a Revolução Farroupilha, que eclodiu no Brasil no ano de 1835.

A sequência do trabalho, em outro tópico, enfatizou a Revolução Farroupilha que, proclamando a independência da República Rio-Grandense, surgiu fundamentada idelogicamente em princípios do liberalismo e do federalismo, buscando autonomia em relação ao poder centralizador estabelecido pela Constituição Brasileira de 1824.

Demonstrou-se que, na tentativa de institucionalizar a Revolução, somente mais de sete anos depois de instaurada foi apresentado um projeto de Constituição. Em 08 de fevereiro de 1843, portanto, no município de Alegrete, surgiu a proposta de Constituição da República Rio-Grandense, apresentada a uma Assembleia Constituinte que se autodissolveu dois dias depois.

Em análise da proposta apresentada, em resposta ao problema levantado no presente trabalho, demonstrou-se que referido projeto (a Constituição de Alegrete) não condizia com os ideais revolucionários presentes no movimento. Por meio dessa constatação, conclui-se que o texto não apresentava instrumentos aptos para a efetivação dos ideais do liberalismo e do federalismo utilizados para impulsionar a Revolução.

De fato, portanto, os princípios que fundamentavam a oposição ao modelo estatal centralizador do poder estabelecido pela Constituição de 1824 não nortearam a tentativa de institucionalização da revolta em relação à Constituição do Império tentada por meio da Revolução Farroupilha.

Assim, apesar de transpor princípios liberais de reconhecer a separação de poderes, afastando o Poder Moderador presente na Constituição de 1824, a Constituição de Alegrete propunha o estabelecimento de uma república unitária, não federativa, sem autonomia para os entes que a compunham. Ademais, a proposta "liberal" convivia com o contexto forte de escravidão no sul do país, altamente marcado pelo conflito marcado pelo episódio dos 


\section{A CONSTITUIÇÃO DE ALEGRETE NA HISTÓRIA CONSTITUCIONAL BRASILEIRA: UMA ANÁLISE A PARTIR DA SOCIOLOGIA DAS CONSTITUIÇÕES}

lanceiros negros, bem como pelo fato de a Constituição de Alegrete considerar como cidadãos apenas os homens livres, sequer mencionando libertos e escravos.

Nesse sentido, conclui-se, portanto, que, a exemplo da própria Constituição Brasileira de 1824, a Constituição de Alegrete, caso fosse promulgada, fazendo-se uma análise sociológico-sistêmica (LUHMANN, 2016), seguiria com o caráter simbólico presente na primeira expressão do constitucionalismo no Brasil (NEVES, 2018), não vinculando juridicamente as decisões políticas (ROCHA; COSTA, 2018). Pouco se aproximaria, assim, dos ideais que impulsionaram a Revolução Farroupilha.

\section{REFERÊNCIAS}

ACKERMAN, Bruce. A ascensão do constitucionalismo mundial. In: SOUZA NETO, C. P.; SARMENTO, D. (orgs.). A constituição do direito: fundamentos teóricos e aplicações específicas. Rio de Janeiro: Lumen Juris, 2007, p. 89-111.

BAKOS, Margaret M. A escravidão negra e os farroupilhas. PICCOLO, Helga I. A Guerra dos Farrapos e a construção do Estado nacional. In. PESAVENTO, Sandra J. et. al (org.). A Revolução Farroupilha: história e interpretação. Porto Alegre: 1985. p. 79-97.

BARRETTO, Vicente de Paulo. Ideologia e política no pensamento de José Bonifácio de Andrada e Silva. Rio de Janeiro: Zahar, 1977.

BOBBIO, Norberto. Estado, governo e sociedade: por uma teoria geral da política. Tradução Marco Aurélio Nogueira. Rio de Janeiro: Paz e Terra: 1987.

BONAVIDES, Paulo; ANDRADE, Paes de. História Constitucional do Brasil. Rio de Janeiro: Paz e Terra: 1991. 
DECANAL, José Hidelbrando. Réquiem, ainda que tarde, para os Farroupilhas. In. PESAVENTO, Sandra J. et. al (org.). A Revolução Farroupilha: história e interpretação. Porto Alegre: 1985. p. 122-127.

\section{DECLARAÇÃO DOS DIREITOS DO HOMEM E DO CIDADÃO. MINISTÉRIO}

PÚPLICO FEDERAL. Disponível em: < http://pfdc.pgr.mpf.mp.br/atuacao-e-conteudos-deapoio/legislacao/direitos-humanos/declar_dir_homem_cidadao.pdf >. Acesso em: 17 mar. 2018 .

DI RUFFÌA, Paolo Biscaretti. Introducción al derecho constitucional comparado. Ciudad de México: Fondo de Cultura Económica, 1998.

FREITAS, Décio. Farrapos: uma rebelião federalista. In. PESAVENTO, Sandra J. et. al (org.). A Revolução Farroupilha: história e interpretação. Porto Alegre: 1985. p. 110-121.

JELLINEK, Georg. Teoría general del estado. Granada: Comares, 2000.

KELSEN, Hans. Jurisdição constitucional. São Paulo: Martins Fontes, 2003.

Teoria Pura do Direito. 8. ed. São Paulo: Martins Fontes, 2009.

LEITMAN, Spencer. Negros Farrapos: hipocrisia racial no sul do Brasil no século XIX. In. Sandra J. et. al (org.). A Revolução Farroupilha: história e interpretação. Porto Alegre: 1985. p. 61-79.

LUHMANN, Niklas. La sociedad de la sociedad. Traducción de Javier Torres Nafarrate. México: Herder, 2007.

O direito da sociedade. São Paulo: Martins Fontes, 2015. 
MALBERG, R. Carré De. Teoria general del estado. Mexico: Fondo de Cultura Económica, 1948.

NEVES, Marcelo. A Constitucionalização Simbólica. São Paulo: Editora Acadêmica, 1994.

Constituição e Direito na modernidade periférica: uma abordagem teórica e uma interpretação do caso brasileiro. São Paulo: Martins Fontes, 2018.

_. Transconstitucionalismo. São Paulo: Martins Fontes, 2009.

PESAVENTO, Sandra J. et. al (org.). A Revolução Farroupilha: história e interpretação. Porto Alegre: 1985.

. Farrapos, liberalismo e ideologia. In. PESAVENTO, Sandra J. et. al (org.). A Revolução Farroupilha: história e interpretação. Porto Alegre: 1985. p. 5-29.

PICCOLO, Helga I. A Guerra dos Farrapos e a construção do Estado nacional. In. PESAVENTO, Sandra J. et. al (org.). A Revolução Farroupilha: história e interpretação. Porto Alegre: 1985. p. 30-60.

ROCHA, Leonel Severo; COSTA, Bernardo Leandro Carvalho. Constitucionalismo Social: Constituição na Globalização. Curitiba: Appris, 2018.

SCHMITT, Carl. La defensa de la constitucion: Estudio acerca de las diversas especies y posibilidades de salvaguardia de la constitucion. Madrid: Tecnos, 1983.

O guardião da Constituição. Tradução de Geraldo de Carvalho. Belo Horizonte: Del Rey, 2007. 
SCIULLI, David. Foundations of Societal Constitutionalism: Principles from the Concepts of Communicative Action and Procedural Legality. British Journal of Sociology, 39, p. 377407, 1988.

SIEYES, Emmanuel Joseph. A constituinte burguesa - que e o terceiro estado?. Rio de Janeiro: Liber Juris, 1986.

TEUBNER, Gunther. Fragmentos constitucionais: constitucionalismo social na globalização. São Paulo: Saraiva. 2016.

THORNHILL, Chris. A Sociology of Constitutions: Constitutions and State Legitimacy in Historical-Sociological Perspective. New York: Cambridge University Press, 2011.

A sociology of Transnational Constitutions: social foundations of the post-national legal structure. London: Cambrigde, 2016. 